\title{
NATURAL TRACE ELEMENT DISTRIBUTION BETWEEN IMMISCIBLE SILICATE AND CARBONATE MELTS IMAGED BY NUCLEAR MICROPROBE.
}

\author{
Esmé van Achterbergh ${ }^{1,2}$, Chris G. Ryan ${ }^{2}$, William L. Griffin ${ }^{1,2}$ and Suzanne Y. O'Reilly ${ }^{1}$ \\ ${ }^{1}$ GEMOC ARC National Key Centre, Australia; ${ }^{2}$ CSIRO Exploration and Mining, Australia
}

\section{INTRODUCTION}

Megacrystalline clinopyroxene-rich lherzolite xenoliths, derived from the lithosphere beneath the Slave craton in Canada were transported to the surface during the eruption of the $\mathrm{A} 154 \mathrm{~N}$ kimberlite ca 50 million years ago. The xenoliths host numerous globular ultramafic silicate-carbonate inclusions which were shielded from interaction with mantle wall-rock by the clinopyroxene host. Quantitative trace element imaging of the globules provide insights into the distribution of trace elements in mantle fluids.

\section{NUCLEAR MICROPROBE IMAGING}

A technique has been developed using the CSIROGEMOC Nuclear Microprobe (Ryan et al., 1999; 2001a) to image the minor- and trace-element components of melt inclusions, and integrate contributions across each inclusion, using the Dynamic Analysis method (Ryan et al., 1995). Dynamic Analysis projects quantitative major and trace element images from PIXE (Particle Induced X-ray Emission) data obtained using the Nuclear Microprobe (NMP), unmixing X-ray spectra to produce images that reject artifacts due to overlapping elements, detector effects (such as escape peaks and tailing) and background. The data are stored in ppm-charge units, enabling images to be directly interrogated for the concentrations of elements in selected areas, line projections, or points. Examples show that this approach can quantitatively image spatial variation in component elements at 1-2 $\mu \mathrm{m}$ resolution and at levels of $\sim 2 \mathrm{ppm}$ and determine reliable melt composition with detection sensitivities down to $0.2 \mathrm{ppm}$ (Ryan et al., 2001b).

PIXE analysis nominally provides data for elements from Si to U, but for this particular application a 200 $\mu \mathrm{m} \mathrm{Al}$ filter was required to reduce the very high yield of major-element Fe X-rays (in order to keep pile-up to a minimum and to protect the fragile detector crystal). This meant that the X-rays of minor and trace elements from $\mathrm{P}$ to $\mathrm{Cr}$ were also attenuated and could not be analysed. The lightest elements emit significant yields of gamma rays; this allowed the qualitative imaging of $\mathrm{B}, \mathrm{F}, \mathrm{Na}, \mathrm{Mg}, \mathrm{Al}$ and Si using PIGE (Particle Induced Gamma-ray Emission), simultaneously with the PIXE maps.

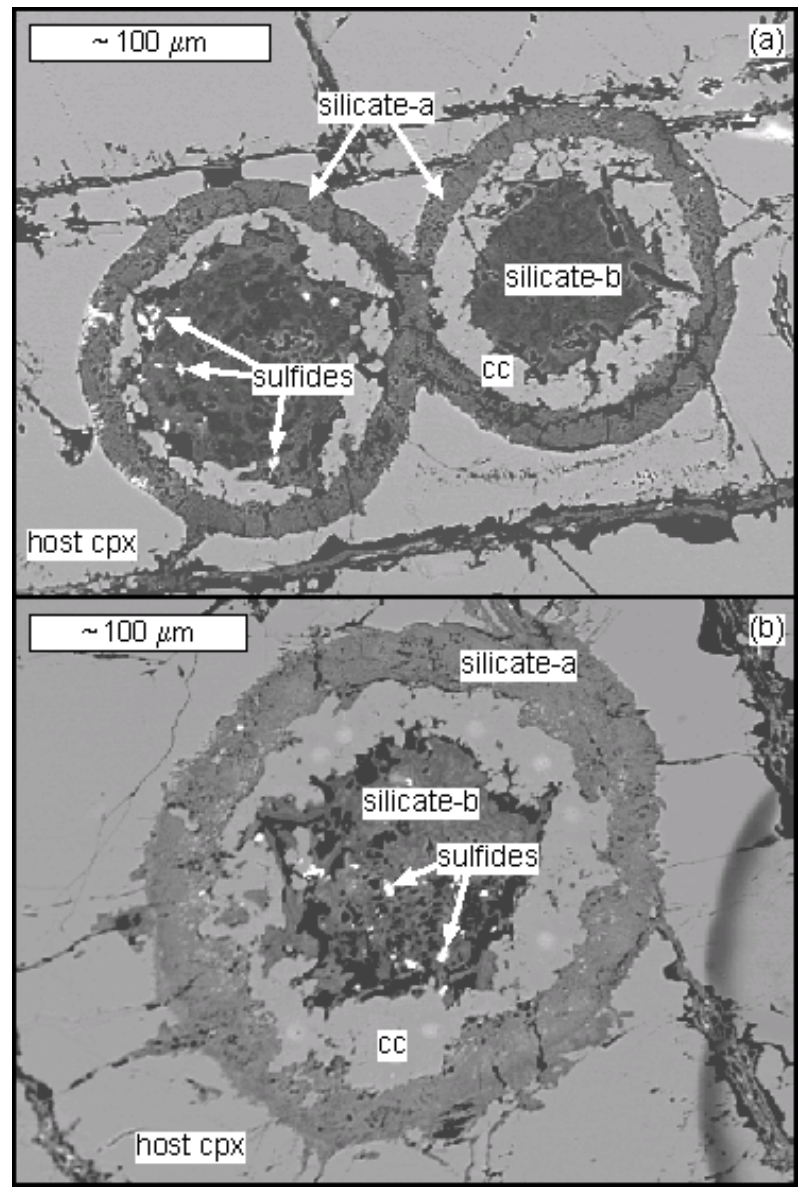

Figure 1: Examples of typical silicate-carbonate globules described in this study (obtained by backscattered-electron analysis). Abbreviations are given in the text. The faint dots in the calcite of (b) are electron microprobe analysis points with a defocused beam. 


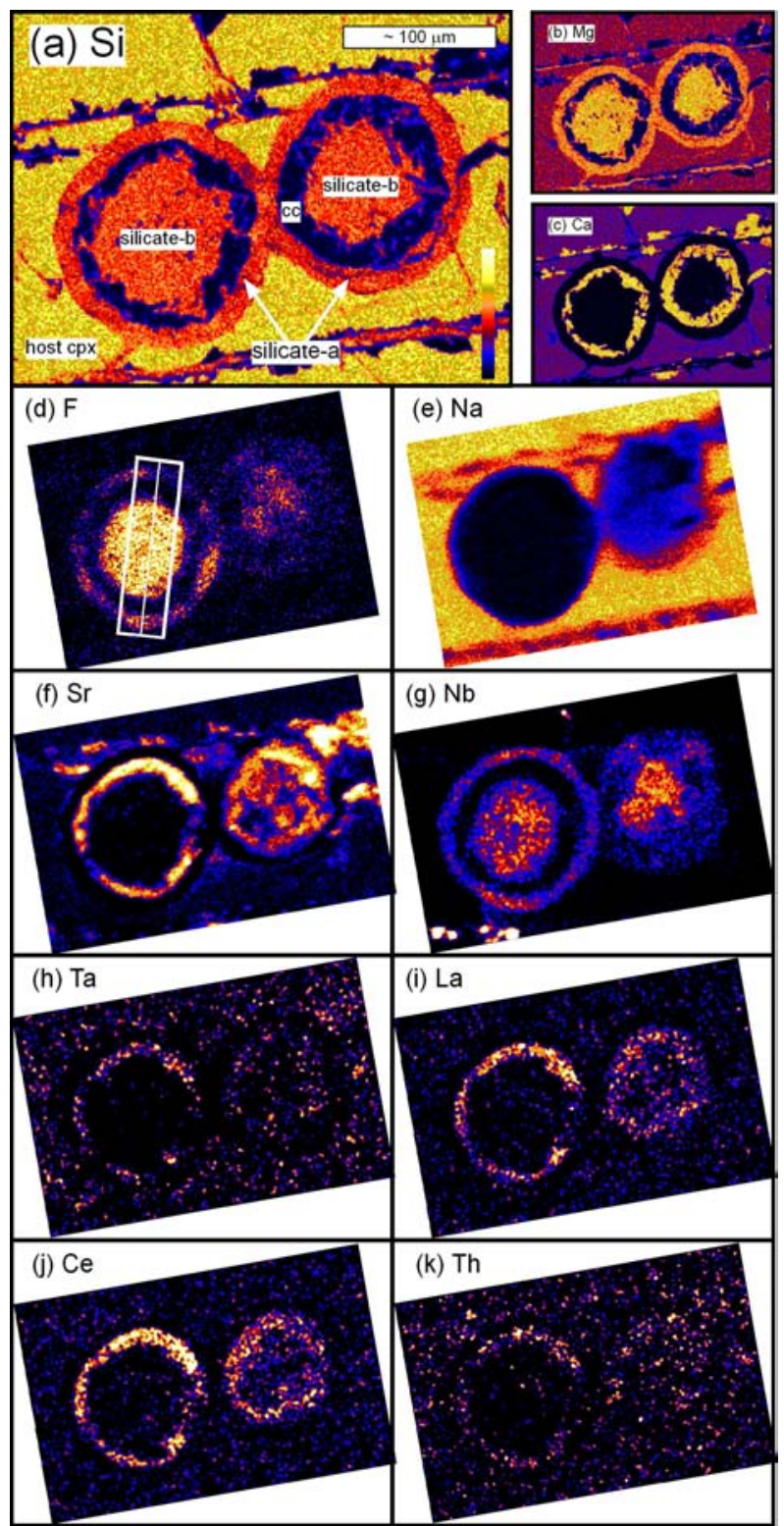

Figure 2: NMP images of the silicate-carbonate globules shown in Fig. 1a. Colour intensity is correlated with concentration; the legend is shown in (a) and indicates increasing concentrations from bottom to top. The majorelement maps for $\mathrm{Si}, \mathrm{Mg}$ and $\mathrm{Ca}$, obtained by EMP analysis, are shown for reference. Images for $\mathrm{F}$ and $\mathrm{Na}$ were obtained by gamma emission analysis (PIGE); all other trace-element images from X-ray emission analysis (PIXE). The NMP images have been rotated slightly to correspond to the EMP images. The position of the traverse illustrated in Fig. 3 is shown in (d); all data within the rectangle are included in the traverse by averaging slices perpendicular to the long axis and projecting the data onto the central line.

\section{SAMPLE DESCRIPTION}

Sample VR43445A is a clinopyroxene macrocryst 1 $\mathrm{cm}$ long that contains ultramafic silicate globules with subordinate carbonate. The globules vary in size from ca $100 \mu \mathrm{m}$ to $2 \mathrm{~mm}$ in diameter. The silicate and carbonate components in the globules occur as concentric rings (Fig. 1); the carbonate component separates an outer ring of silicate glass (silicate-a; mg\# $=85.1)$ from a silicate-glass core (silicate- $\mathrm{b} ; \mathrm{mg} \#=$ 91.4). The carbonate component crystallised as calcite (cc). Small grains of pyrite and pyrrhotite $(<4 \mu \mathrm{m}$ in diameter) occur in the silicate component of some inclusions.

\section{ANALYTICAL RESULTS}

The bulk major-element compositions of individual globules were calculated using electron microprobe (EMP) analyses of the constituent phases and modal abundances derived from image analysis and are typical of Group I kimberlites. Bulk trace-element compositions were obtained by integrating the entire inclusion volume from the PIXE images. The data overlap with Mitchell's (1986) trace-element data for uncontaminated kimberlites as well as data from a recent compilation of Grégoire et al. (2002; references therein). The bulk compositions of the globules are discussed in more detail elsewhere in these proceedings (Van Achterbergh et al., 2003).

$\mathrm{Si}, \mathrm{Mg}, \mathrm{Ca}$ and trace-element images of the pair of silicate-carbonate globules shown in Fig. 1a are illustrated in Fig. 2. The inclusions are strongly depleted in $\mathrm{Na}$ relative to the surrounding clinopyroxene host (Fig. 2e). The NMP images illustrate that $\mathrm{F}$ and $\mathrm{Nb}$ (also $\mathrm{Ni}$; not shown) preferentially partition into the silicate components, whereas $\mathrm{Br}$ (not shown), $\mathrm{Sr}, \mathrm{Ta}, \mathrm{La}, \mathrm{Ce}, \mathrm{Pb}$ (not shown) and Th concentrate in the carbonate component. It is significant to note that $\mathrm{F}$ and $\mathrm{Br}$, although both halogens, partition differently ( $F$ concentrated in silicate, $\mathrm{Br}$ in carbonate). Similarly, $\mathrm{Nb}$ and $\mathrm{Ta}$ are both in the same group on the periodic table but their concentrations in these inclusions are decoupled $(\mathrm{Nb}$ concentrated in silicate, Ta in carbonate). A traverse (position shown in Fig. 2d) across one of the globules was extracted from the images and the data are plotted in Fig. 3 to further illustrate this $\mathrm{F}-\mathrm{Br}$ and $\mathrm{Nb}-\mathrm{Ta}$ fractionation, as well as the tendency of $\mathrm{Sr}, \mathrm{La}$ and $\mathrm{Ce}$ to concentrate in the carbonate component. Quantitative data for $\mathrm{F}$ in Fig. 3 was obtained by normalising the yield of $F$ gamma rays to the average F-yield/Fconcentration ratio of the silicate glass, where the $\mathrm{F}$ content of the silicate glass was determined independently by EMP point analysis (with 20 s count times). 


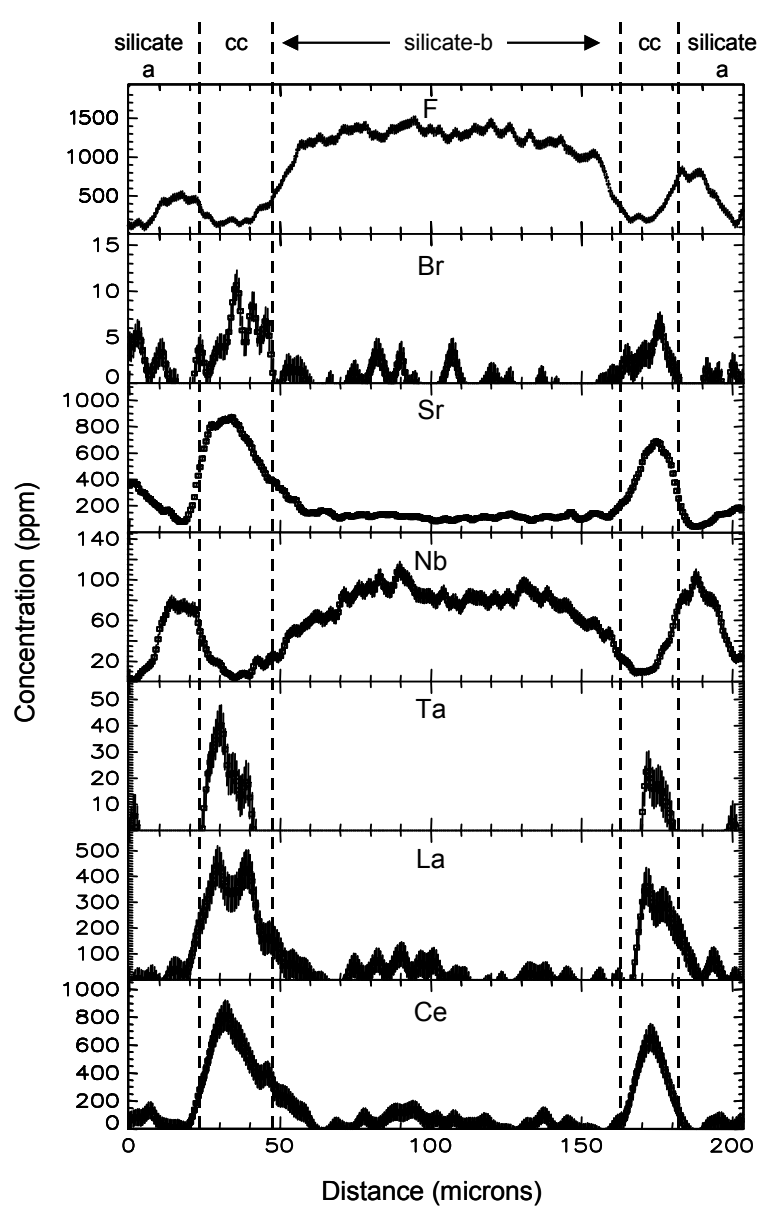

Figure 3: Traverse across a silicate-carbonate globule (position of traverse shown in Fig. 2d) extracted from the NMP images. The data are plotted as points with uncertainty estimates, but due to the small step-size (ca $2 \mu \mathrm{m})$ appear on the plots as lines with the thickness of the lines an indication of the 1sigma uncertainty. The dashed lines separate the different components as shown at the top of the plot (abbreviations as Fig. 1). The data illustrate the fractionation of $\mathrm{F}$ and $\mathrm{Br}$, and $\mathrm{Nb}$ and $\mathrm{Ta}$ between the silicate and carbonate components, as well as the extreme enrichment of REE in the carbonate.

Trace-element data for the calcite are plotted in Fig. 4; the calcite is unusually enriched in rare earth elements (REE).

\section{DISCUSSION}

The globules are interpreted as carbonate-bearing ultramafic silicate melts, similar to Group I kimberlite (Van Achterbergh et al., 2003). The low $\mathrm{Na}$ of the globules relative to the surrounding host (e.g. Fig. 2e) is

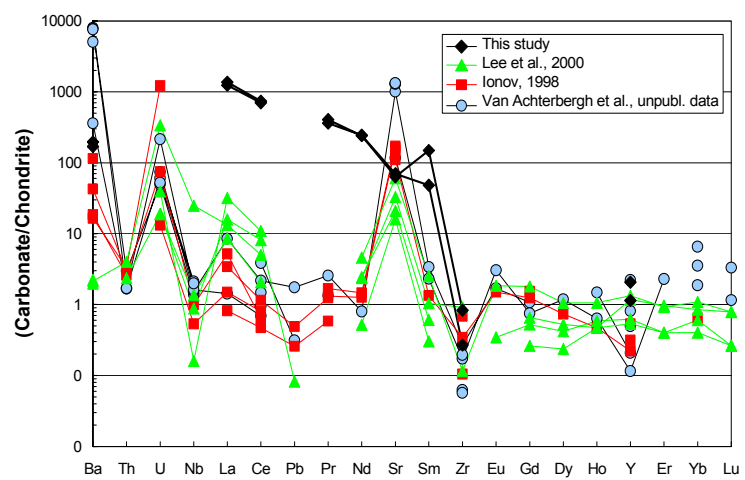

Figure 4: Chondrite-normalised trace-element concentrations of the carbonate component obtained by extracting the carbonate data alone from the NMP images (black diamonds). The data are compared with data for other mantle-derived carbonates (Ionov, 1998; Lee et al., 2000; Van Achterbergh et al., unpubl. data). The data from this study show extreme enrichment in the REE $\mathrm{La}, \mathrm{Ce}, \mathrm{Pr}, \mathrm{Nd}$ and $\mathrm{Sm}$ compared with other carbonates. REE heavier than $\mathrm{Sm}$ are below the limits of detection by NMP.

interpreted as evidence that they are not in equilibrium with the clinopyroxene $(\mathrm{Na}$ is incompatible in clinopyroxene and will concentrate in the melt) and that they therefore could not have formed by in situ partial melting. The globules most likely formed by partial melting of carbonated peridotite at deeper levels (lower lithosphere/upper asthenosphere), migrated upwards and were trapped in the host pyroxene shortly before kimberlite eruption (Van Achterbergh et al., 2003).

The concentric microstructures of the silicate-carbonate globules are interpreted as evidence for the immiscible separation of silicate and carbonate melts after the inclusions were trapped in the host clinopyroxene. The outer silicate ring is interpreted either as a reaction rim of the melt with the host cpx or a zone of initial crystallisation; this is interpreted as shifting the bulk composition of the residual melt to higher $\mathrm{CO}_{2}$ content and triggered immiscible separation of a carbonate component and a second silicate component, concentrated in the core. The change in bulk composition may have been accompanied by slow cooling which may have played a part in the immiscible separation.

Common mantle-derived carbonates do not contain high levels of the REE. C.-T. Lee et al. (2000) compiled data for mantle-derived carbonate minerals and demonstrated that total REE ( $\Sigma$ REE) do not exceed ca $30 \mathrm{ppm}$ in the carbonates they considered. In this 
study, summing the 5 REE that were detected by NMP ( $\mathrm{La}, \mathrm{Ce}, \mathrm{Pr}, \mathrm{Nd}$ and $\mathrm{Sm}$ ) yields a value more 2700ppm; this value is closer to the carbonatite range of $3000-$ 10000 ppm (C.-T. Lee et al., 2000). The anomalously high concentrations of REE in the calcite further suggests that it is not a cumulate that formed by fractional crystallisation and that it most likely represents the frozen product of a carbonate magma rich in incompatible trace elements as suggested by Moine et al., (2002).

The almost pure $\mathrm{CaCO}_{3}$ melt represents the so-called "forbidden" composition ( $\left.>80 \% \mathrm{CaCO}_{3}\right)$ of W.J. Lee et al., (1994) who demonstrated experimentally that such melts cannot form by immiscible separation of silicatecarbonate parent melts at mantle pressures. This suggest that there are additional components/elements in natural systems that play an important role in silicate-carbonate immiscibility and which have not been incorporated in the experiments or that the melts became immiscible at low pressure in the crust after kimberlite eruption or a combination of both.

\section{REFERENCES}

Grégoire M., Bell, D.R. and Le Roex, A.P., 2002. Trace element geochemistry of phlogopite-rich mafic mantle xenoliths: their classification and their relationship to phlogopite-bearing peridotites and kimberlites revisited. Contrib. Mineral. Petrol. 142, 603-625.

Ionov, D., 1998. Trace element composition of mantlederived carbonates and coexisting phases in peridotite xenoliths from alkali basalts. J. Petrol. 39, 1931-1941.

Lee, C.-T., Rudnick, R.L., McDonough, W.F., and Horn, I., 2000. Petrologic and geochemical investigation of carbonates in peridotite xenoliths from northeastern Tanzania. Contrib. Mineral. Petrol. 139, 470-484.

Lee, W.-J., Wyllie, P.J., and Rossman, G.R., 1994. CO2-rich glass, round calcite crystals, and no liquid immiscibility in the system $\mathrm{CaO}-\mathrm{SiO}_{2}-\mathrm{CO}_{2}$. Am. Mineral. 79, 1135-1144.

Mitchell, R.H., 1986. Kimberlites: Mineralogy, Geochemistry and Petrology. Plenum Press, New York and London.

Moine, B. N., Sheppard, S. M. F., O'Reilly, S. Y, Grégoire, M., Delpech, G., Renac, C., Cottin J.Y., and Giret, A. 2002. Carbonatite melt in oceanic upper mantle beneath the Kerguelen Plateau. Geochim. Cosmochim. Acta, $12^{\text {th }}$ Annual Goldschmidt Volume Abstracts, August 2002, A518.

Ryan, C.G., Jamieson, D.N., Churms, C.L. and Pilcher, J.V., 1995. A New Method for On-Line True Elemental Imaging using PIXE and the Proton Microprobe. Nucl. Instr. Meth. B104, 157-165.

Ryan, C.G., Jamieson, D.N., Griffin W.L. and Cripps, G., 1999. The CSIRO-GEMOC Nuclear Microprobe: a high performance system based on a new closely integrated design. Nucl. Instr. Meth. B158, 18-23.

Ryan, C.G., Jamieson, D.N., Griffin, W.L., Cripps G. and Szymanski, R., 2001a. The New CSIRO-GEMOC Nuclear Microprobe: First Results, Performance and Recent Applications. Nucl. Instr. Meth. B181, 12-19.

Ryan, C.G., Van Achterbergh, E., Griffin, W.L., Pearson, N.J., O'Reilly, S.Y. and Kivi, K., 2001b. Nuclear microprobe analysis of melt inclusions in minerals: Windows on metasomatic processes in the earth's mantle. Nucl. Instr. Meth. B181, 578-585.

Van Achterbergh, E., Griffin, W.L., O'Reilly, S.Y., Ryan, C.G., Pearson, N.J., Kivi, K. and Doyle, B., 2003. Melt inclusions from the deep slave lithosphere: constraints on the origin and evolution of mantlederived carbonatite and kimberlite. These proceedings.

Contact: E van Achterbergh, CSIRO Exploration and Mining, PO Box 136, North Ryde, NSW 1670, Australia, E-mail: esme.vanachterbergh@csiro.au 